\title{
Biological Activities and Novel Applications of Chalcones ${ }^{1}$
}

\author{
Atividades Biológicas e Novas Aplicações das Chalconas
}

\author{
DÍAZ-TIELAS, C. ${ }^{2}$, GRAÑA, E. ${ }^{2}$, REIGOSA, M.J. ${ }^{2}$, and SÁNCHEZ-MOREIRAS, A.M.²
}

\begin{abstract}
This review provides information on the biological activities of chalcones (whether natural or synthetic derivatives) on different organisms, as well as an overview of the functions and possible new applications of these plant secondary metabolites on crop protection, as eco-friendly pesticides and weed control agents. Naturally occurring chalcones have been used in traditional medicine for many years; however, recent scientific advances have shown that these molecules have a broad range of biological activities in a variety of organisms. A review on the major sources of chalcones and the main molecular events involved in the modes of action of these natural products is achieved. Chalcones are molecules with a broad spectrum of biological activities, which are of great interest in agriculture to control weeds and unwanted pests.
\end{abstract}

Keywords: mode of action, secondary metabolites, crop protection, pesticide, fungicide, antiviral, phytotoxicity.

RESUMO - Esta avaliação fornece informações sobre as atividades biológicas de chalconas (quer derivados naturais ou sintéticos) em diferentes organismos, bem como uma visão geral das funções e eventuais novas aplicações desses metabólitos secundários de plantas em proteção de cultivos e pesticidas orgânicos e para controlar as plantas daninhas. Durante muitos anos têm sido utilizadas na medicina tradicional chalconas de ocorrência natural; no entanto, os recentes avanços cientificos têm mostrado que essas moléculas têm vasta gama de atividades biológicas em uma variedade de organismos. Este estudo permite ter uma ideia das principais fontes de chalconas e dos eventos moleculares envolvidos nos principais mecanismos de ação desses produtos naturais. As chalconas são moléculas com um largo espectro de atividade biológica, de grande interesse na agricultura para controlar plantas daninhas e pragas indesejadas.

Palavras-chave: modo de ação, metabólitos secundários, proteção de cultivos, pesticida, fungicida, antiviral, fitotoxicidade.

\section{INTRODUCTION}

Nature is a source of chemical diversity that should not be underestimated. Along the history, humans have exploited the different biological activities of many terrestrial and marine organisms, most of the times in an intuitive way. Antitumor, anti-inflammatory, anti-diabetic, anti-bacteria, anti-fungal, and many other activities have been investigated for natural-producing compounds during the last years (Verpoorte, 2000; Dewick, 2002; Prashar et al., 2012). Nowadays, an emerging but every time more priority interest is focused on the role of natural compounds in crop development and protection. We should not look down at the strong selection that nature has done for centuries on this plethora of compounds. Exploring the chemistry of molecules already selected by nature to play a role in ecological defense appears as an essential starting point to look for new pest control products.

During the last decades, large amounts of synthetic pesticides have been used mainly in intensive agriculture for crop protection in a non controlled-way. The abuse of synthetic herbicides in the field has led to the emergence of weeds agrochemical-resistant

\footnotetext{
Recebido para publicação em 12.12.2015 e aprovado em 16.2.2016.

2 Faculty of Biology, University of Vigo, Vigo (Spain), <carladt@uvigo.es>.
} 
(Brazier et al., 2002; Powles and Yu, 2010) with strong economic losses, potential health risks and environmental contamination (Pesce et al., 2011; Magnusson et al., 2013). Pesticides (fungicides, insecticides and bactericides) have been broadly searched among natural compounds, but also herbicides, bioherbicides, and new more ecologically friendly herbicides have being assayed during the last years (Duke et al., 2000; Copping and Duke, 2007; Dayan et al., 2009). The aim of these investigations is to look for compounds with new mechanisms of action different from those used by synthetic agrochemicals, in order to obtain effective compounds with low environmental impact.

When searching for new compounds with a desirable biological activity, such as herbicidal activity, it is useful to select candidates that show a broad spectrum of demonstrated biological activities. Chalcones and chalcone derivatives have a huge number of different biological activities, which are highly appreciated in many areas. In fact, chalcones are bioactive against virtually all eukaryotes and some prokaryotes, and their molecular targets are numerous (Zhou and Xing, 2015).

During the last decades, numerous investigations were carried out on the pharmacological activities of naturally occurring and synthetic chalcones, i.e. the anti-inflammatory, the antioxidant, the antiinfective (such as antileishmanial and antimalarial, and anti-tuberculosis), the antiviral, and above all the anticancer and antitumor activities of these compounds. The works of Ni et al. (2004), Orlikova et al. (2011), Sahu et al. (2012) and Zhang et al. (2013) are excellent reviews that shed light on the structure and mechanisms of action of chalcones with therapeutic properties. Actually, a number of chalcones have been successfully developed as commercial drugs for treatment of some digestive system diseases; and others are being clinically assayed for the treatment of cancer, cardiovascular diseases, and viral infections (Ni et al., 2004).

Some chalcones target the inflammation signaling pathways in cells, being highly anti-inflammatory and, consequently, effective against cardiovascular diseases (ZHONG et al., 2015) and tumor promotion
(Orlikova et al., 2011). Chalcone effects on tumor initiation, invasion and metastasis have been comprehensive reviewed by Orlikova et al. (2011) and Zhang et al. (2013). The antiproliferative activity of chalcones is due to their capacity to inhibit tubulin assembly and stop uncontrolled proliferation of cancer cells. The induction of apoptosis by chalcones often comprises the mitochondrial pathways, down-regulation of anti-apoptotic proteins, and/or death receptor pathways (Pan et al., 2005; Nishimura et al., 2007; Sakai et al., 2012). Some chalcones may also induce apoptosis through generation of reactive oxygen species (ROS) (Motani et al., 2008), notwithstanding being known as antioxidant molecules. The pro-oxidant activity of chalcones may be conferred by their strong reactivity with thiol groups in living organisms, by the induction of a series of reactions with hydroxyl radicals in living cells, or by reducing the antioxidant mechanisms, such as the glutathione content (Kachadourian; Day, 2006). Furthermore, some chalcones may have dual functions, inducing PCD in some cell types, and preventing against oxidative cytotoxicity in others (Lee et al., 2015; Zhong et al., 2015). Chalcones induce also programmed cell death in other eukaryotes, such as the protozoan Plasmodium falciparum (Sharma et al., 2012), and the plant Arabidopsis thaliana (Diaz-Tielas et al., 2012).

Generally, the chemical structure of chalcones, in particular the characteristic $\alpha, \beta$-double bond and the presence and positions of the hydroxyl groups (or their chemical substituents), determines the most of their biological activities (Orlikova et al., 2011). Chalcones are multifunctional molecules, since one particular structure can show multiple biological activities. For example, licochalcone A has been shown to contribute to the great antioxidant capacity of licorice and to act as bactericide, antileishmanial, antimalarial, anti-inflammatory and cell cycle inhibitor and (Friis-Møller et al., 2002; Fu et al., 2004; Furusawa et al., 2009).

Based on this diversity of biological activities, this review provides a general overview of the origin, sources, and biological activities of chalcones, and a brief discussion on the most important molecular sites of 
action of these compounds in different organisms. Finally, the biological activities of chalcones that are of interest in agriculture and plant production, as well as the potential novel applications of chalcones in agricultural systems, will be also reviewed.

\section{STRUCTURE, BIOSYNTHESIS AND ROLES OF CHALCONES IN NATURE}

Chalcones, 1,3-diphenyl-2-propen-1-one (Piñero et al., 2006), are open chain flavonoids with a 15-carbon structure arranged in a $\mathrm{C}_{6}-$ $\mathrm{C}_{3}-\mathrm{C}_{6}$ configuration. They consist in two phenolic rings (A and $\mathrm{B}$ rings) connected by a 3C bridge (Iwashina, 2000) with a double bond between á- and â-positions, which confers them a particularly singular structure.

In higher plants, chalcones are synthesized by the enzyme chalcone synthase from one molecule of $p$-coumaril-CoA and three molecules of malonyl-CoA. The aminoacid L-phenylalanine, which is formed in the shikimic acid pathway, is converted to $p$-coumaril-CoA through the phenylpropanoid pathway, resulting in the formation of the aromatic $\mathrm{B}$-ring and the $3 \mathrm{C}$ bridge of chalcone $\left(\mathrm{C}_{6}-\mathrm{C}_{3}-\right)$. The aromatic A-ring is formed after the condensation of three molecules of malonyl-CoA $\left(-\mathrm{C}_{6}\right)$ (Austin and Noel, 2003; $\mathrm{Yu}$ and Jez, 2008).

Once synthesized, chalcone has three main destinations in plant metabolism. It can be used to produce aurones by the aureusidin synthase; to form glycosyl conjugates, which are yellow flower pigments that accumulate in plants; and in most cases, it can be converted to naringenin by the action of chalcone isomerase. Chalcone isomerase "type I", broadly found in higher plants (except leguminous plants) produces the 5-hydroxyflavanone naringenin, which is the biosynthetic precursor of virtually all flavonoids (flavones, isoflavones, flavonols, condensed tannins and anthocyanins) (Ayabe and Akashi, 2006; De La Rosa, 2009).

Chalcones, as other flavonoids and phenolic compounds, play an important ecological role as signaling molecules in plant-microbe symbioses, being essential for plant survival. Chalcones from leguminous plants are exuded into the rhizosphere strongly inducing nod genes in Rhizobium meliloti (Maxwell et al., 1989). These molecules might also play a role in natural systems as biochemical regulators of plant dispersal in Pityrogramma calomelanos ferns (Star, 1980). In addition, glycosylconjugated chalcones are widely distributed flower pigments, having an important role in pollination. Due to the $\alpha, \beta$-double bond of the $3 \mathrm{C}$ bridge, chalcones show a distinctive yellow color (Iwashina, 2000). Pigment chalcones are particularly spread in the subtribe Coreopsidinae of Compositae, such as the genera Dahlia, Coreopsis or Cosmos and in Dianthus caryophyllus (Caryophyllaceae) (Harborne, 1966).

\section{NATURAL AND SYNTHETIC SOURCES OF CHALCONES}

In nature, chalcones are usually found as chalcone aglycones and chalcone O-glycosides, but they can be also modified by hydroxylation, condensation or methylation. These compounds are widely distributed in foods and beverages such as vegetables, fruits, tea, soy-based foodstuff and spices. They are present in numerous families of dicotyledonous plants, and in some monocotyledonous, pteridophytes and gymnosperms (Iwashina, 2000), but are synthesized as major components in the families Asteraceae, Moraceae, Fabaceae and Aristolochiaceae.

The members of the genus Bidens and Coreopsis of the family Asteraceae are noted for their high content of chalcones (Redl et al., 1993; Shang et al., 2013). Their occurrence is also particularly relevant in the tribe Heliantheae, and several chalcones have been isolated from Helianthus annuus (Macias et al., 1997). Several chalcones have been also found in the aerial roots of Ficus microcarpa, the roots, stems and leaves of the genus Morus, the leaves and/or fruits of the genus Artocarpus and in members of the genus Dorstenia, all belonging to the family Moraceae (Abegaz et al., 2002; Jayasinghe et al., 2004; Yang et al., 2010). In the family Fabaceae, chalcones are present in Desmodium renifolium, Psoralea corylifolia, roots of the genus Sophora, the genus Glycyrrhiza, and the genus Dalbergia (Bhatt and Dayal, 1992; Friis-Møller et al., 2002; LI et al., 2014). Chalcones are also present in plant species from other families, 
sometimes at very high concentrations, as in the yellow sap of Angelica keiskei (Nishimura et al., 2007) or in members of the genus Scutellaria (Shang et al., 2010).

The molecular structure of chalcones (the $\mathrm{C}_{6}-\mathrm{C}_{3}-\mathrm{C}_{6}$ skeleton) seems to be a perfect starting point to synthesize new derivative compounds. During the last years, the interest on these molecules has increased, mostly due to their potential use as drugs against several human diseases. The synthesis of new compounds based on the chalcone skeleton provides a new world of possibilities for biological activities and applications. Nevertheless, there are hundreds of nonexplored sources of natural chalcones, which should not be forgotten, since the pressure of evolution has selected the compounds with a more accurate and effective biological activity in natural ecosystems.

\section{THE POTENTIAL USE OF CHALCONES IN AGRICULTURE AND PLANT PROTECTION}

The prospective practical application of chalcones as eco-friendly plant growth regulators and defense agentsin agriculture and plant production is of great relevance and worthy of discussion. Due to the numerous biological activities of these secondary metabolites, there are many possibilities for their use in agriculture. Regarding pest defense and weed control, the most interesting biological activities of chalcones are the bactericide, antifungal, antihelmintic, insecticidal, insect antifeedant, antiviral and phytotoxic activities. The chemical structures of some chalcones cited in the text with a potential use in agriculture and plant protection are shown in Table 1.

\section{Fungicides}

Several naturally occurring chalcones are toxic against a large variety of plant pathogens that cause pests and important agronomic and economic losses worldwide. Chalcone has been found to exert toxicity against 5 fungal pathogens (Colletotrichum falcatum, Curvularia pallescens, Ceratocystis paradoxa, Fusarium moniliforme, Periconia atropurpurea and Ustilago scitaminea), being even more active than commercial fungicides (Rao et al., 1994). Two natural chalcones isolated from the leaves of Myrica serrata, 2',4'-dihydroxy-3',5'-dimethyl-6'methoxychalcone and stercurensin, showed a strong inhibitory effect on the growth of Cladosporium cucumerinum, a fungus that typically affects cucumber (Gafner et al., 1996). The 2',4'-dihydroxy-3'-methoxychalcone and the 2',4'-dihydroxychalcone isolated from Zuccagnia punctata (Fabaceae) were found to be active against the pathogenic fungi Phomopsis longicolla, Alternaria alternate, Fusarium equiseti, $F$. graminearum, $F$. verticillioides, Colletotrichum truncatum and Sclerotium bataticola, and if used at the concentration of $6.25 \mu \mathrm{g} / \mathrm{mL}$ completely inhibited the growth of $P$. longicolla and C. truncatum (Svetaz et al., 2004; Jimenez et al., 2014). As well, five chalcones isolated from Artocarpus nobilis (Moraceae) were found to have antifungal activity against Cladosporium cladosporioides, which typically affects wheat, or against Aspergillus niger, which causes black mould in certain fruits and vegetables (Jayasinghe et al., 2004; Thirunarayanan and Vanangamudi, 2014).

\section{Antivirals}

A reduced number of studies have been done on the anti-infective activity of chalcones against plant viruses, though the antiviral activity of chalcones against the tomato ringspot virus (ToRSV) has been reported (Malhotra et al., 1996; Onylagha et al., 1997). In a first study, the 2-hydroxychalcone was found to weakly inhibit ToRSV infectivity on Chenopodium quinoa (Malhotra et al., 1996). However, in 1997, Onyilagha and collaborators found higher antiviral activities after testing 21 chalcones. This study demonstrated that antiviral activity is activated by hydroxylation of the A-ring at 2',3',4' positions and B-ring at C-4', suppressed by hydroxylation at C-5', and reduced by methoxylation of the B-ring. In fact, 2', 3', 4', 4-tetrahydroxychalcone inhibited ToRSV infectivity in a $69 \%$, while many other chalcones induced around a 50\% inhibition.

\section{Nematicides, insect deterrents and antifeedants}

Chalcones are compounds highly toxic for many phytoparasitic nematodes, even more than some commercial nematicidal as in the 
Table 1 - Chemical structures and biological activities of some chalcones of importance for agriculture and plant protection

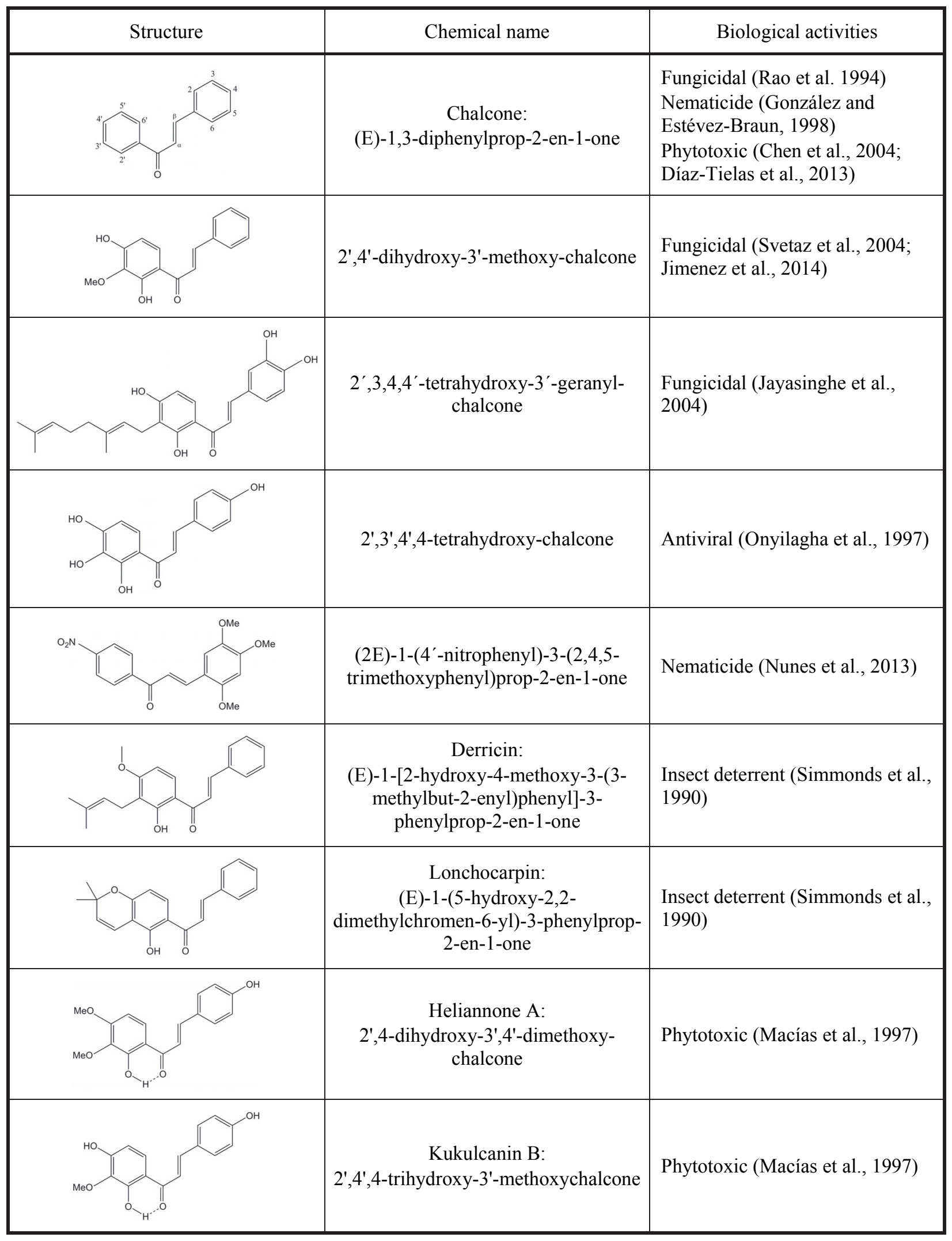


case of trans-chalcone that showed a strong nematicide and nematostatic action against the potato cyst nematodes (González; EstévezBraun, 1998), important parasitic nematodes in terms of economic and agronomic losses. Many synthetic chalcones are highly active against Meloidogyne exigua that causes important coffee crop losses (Nunes et al., 2013). The chalcone (2E)-1-(4'-nitrophenyl)-3(2,4,5-trimethoxyphenyl) prop-2-en-1-one showed stronger nematicide activity than the commercial nematicide carbofuran. This chalcone acts presumably inhibiting the enzyme caffeic acid 3-O-methyltransferase, thanks to three methoxy groups at positions 2, 4 and 5, which seem to be the main responsible for the nematicide effect.

The insecticidal bioactivity of chalcones is really interesting, since insect pests are the main cause of agronomic losses. The effectiveness of chalcones is enhanced by the presence of electron-withdrawing substituents in ring $A$ and electron-withdrawing or electron-releasing substituents in ring $B$. A group of synthetic chalcones has been found to be insecticidal against Plutella xylostella, which is considered one of the most destructive pests of crucifers worldwide (Kumar et al., 2012). The naturally-occurring chalcones lonchocarpin, derricin, derricidin and isocordoin, isolated from Lonchocarpus neuroscapha, showed deterrent activity against larvae of Spodoptera littoralis and S. exempta (Simmonds et al., 1990), which are pests able to destroy crops rapidly. Chalcone derivatives are also active antifeedant agents against larvae of Achaea janata, which feeds on both genera, Brassica and Ficus (Thirunarayanan and Vanangamudi, 2014).

\section{Phytotoxicity}

The phytotoxic effects of chalcones on plant metabolism have been extensively investigated to deeply evaluate the effects of these secondary metabolites as plant growth regulators and/or new potential bioherbicides.

Chalcones are phytotoxic compounds that affect a variety of plant species prepossessing the germination process and root and/or shoot growth (Chen et al., 2004; Yun et al., 2009; Díaz-Tielas et al., 2013). Slightly variations of chalcones structure may confer different biological activity with different phytotoxic effects, i.e. the two chalcones isolated from sunflower, kukulcanin B (2', 4',4-trihydroxy-3'-methoxychalcone) and heliannone A (2',4-dihydroxy-3',4'-dimethoxychalcone). Kukulcanin B showed inhibitory activity on the shoot growth of Lycopersicon esculentum, while heliannone A inhibited germination of $L$. esculentum and germination and shoot growth of Hordeum vulgare (Macias et al., 1997). The divergences of the biological effects were attributed to the variations in number and position of free hydroxyl groups in these two molecules. As well, different tested concentrations of chalcones may induce different phytotoxic effects. For example, 100 and $200 \mu \mathrm{M}$ chalcone $(1,3-$ diphenyl-2-propen-1-one) treatment reduced root growth and total fresh weight of Zea mays, but did not affect root growth at higher and lower concentrations (Chen et al., 2004; Díaz-Tielas et al., 2013).

Regarding the use of natural products for weed management, it is important to select the compounds with the higher activity at the lower concentration. Likewise, these compounds should show plant specificity, being toxic not to the crops but to their associated weeds. In this way, trans-chalcone (1,3-diphenyl-2-propen-1-one) was found to be phytotoxic against a variety of weeds but did not affect the related crop species. Moreover, in some cases the growth rate of these crops was stimulated (Diaz-Tielas et al., 2013). According to this, trans-chalcone could be used for weed control in the following agricultural systems: Oryza sativa-Echinocloa crus-galli, Zea mays-Amaranthus retroflexus, and Triticum aestivum-Plantago lanceolata. Although these findings suggest a great potential of chalcones as selective bioherbicides in a variety of agricultural systems, elucidating their mode/s of action is an indispensable task for the effective use of these secondary metabolites in the field.

Previous studies showed the inhibitory activity of chalcone on two key enzymes of phenylpropanoid metabolism: the phenylalanine ammonia ligase (PAL, EC 4.3.1.24) (Chen et al., 2011) and the 4-coumarate: CoA ligase (4CL, EC 
6.2.1.12), implicated in lignin biosynthesis (Chen et al., 2005; Yun et al., 2009). As lignin synthesis is necessary for plant growth and development, these studies suggested that the inhibition of the enzyme 4CL by chalcones, and the consequent lower rate in the synthesis of lignin, may be the reason for the inhibited plant growth. Further studies demonstrated a correlation between the inhibition of root growth and the strong decline in the activity of root peroxidases (Diaz-Tielas et al., 2012), implicated in lignin biosynthesis and ROS production (Chen and Schopfer, 1999), compounds necessary for cell growth and differentiation.

Our group has previously performed some studies about the effects of transchalcone on the plant model species Arabidopsis thaliana to deepen in the knowledge of the mode of action of chalcones on plant metabolism. Consistent with other assays, trans-chalcone inhibited root growth at very low concentrations (Diaz-Tielas et al., 2012), with a $50 \%$ reduction of root growth $\left(\mathrm{IC}_{50}\right)$ at only $35 \mu \mathrm{M}$ and $80 \%$ reduction $\left(\mathrm{IC}_{80}\right)$ at $73 \mu \mathrm{M}$. Furthermore, chalcone induced PCD in Arabidopsis roots and loss of photosynthetic pigments at only $35 \mu \mathrm{M}$. Depolarization of the mitochondria trans-membrane potential $\left(\Delta \Psi_{\mathrm{m}}\right)$, activation of cell detoxification mechanisms (Golgi complex, vacuoles and autophagosomes), degradation of organelles, lipid accumulation, and condensation of the mitochondria have been detected after chalcone treatment.

However, the phytotoxic effects of transchalcone on adult plants of Arabidopsis thaliana were quite different from those described for seedlings (Diaz-Tielas et al., 2013). Transchalcone inhibited growth and development of Arabidopsis adult plants, affecting much more the aerial parts than the roots. This natural compound seemed to induce early senescence by affecting the photosynthetic efficiency of the old leaves. In general, trans-chalcone acts as an inhibitor of photosystem II by inhibiting electron transport chain dynamics on Arabidopsis plants. Trans-chalcone treated plants could not develop regulated strategies to dissipate the excess of energy, which may be irreversibly harming the photosynthetic apparatus.
Overall, chalcones are highly phytotoxic molecules and the works performed resulted in very promising results, although further studies on the mode of action and the biological effects of chalcones in the field are necessary to make real the use of these secondary metabolites in pest control and weed management.

Summarizing, chalcones are versatile molecules with a great range of biological activities and a great variety of application areas. The utility of these molecules on the prevention and treatment of human cancer has been extensively investigated. Here we emphasized the promising biological activities of chalcones as bactericides, insecticides, fungicides, anti-viral and plant growth regulators; although more investigations are needed to fully understand the molecular mechanisms involved.

The structure of chalcones, in terms of number and position of the hydroxyl groups and the á,â-double bond, is a key factor in the determination of their biological activity. An approximation to the chemical structure of novel chalcones (naturally or derivatives) and their comparison to molecules with known biological activities could be an important tool to elucidate their possible biological effects. However, in spite of their structural diversity, chalcones show the same molecular targets in different studies. Alterations of the redox status, inhibition of mitochondrial electron transport chain or/and induction of PCD, are all together common effects of chalcones in eukaryotic cells. The main reason for the wide range of biological activities of these natural compounds, can be sought in the fact that their principal targets are highly conserved in all eukaryotic kingdoms.

\section{ACKNOWLEDGEMENTS}

This work was supported by the Project No AGL2013-41281-R of the Spanish Ministry of Economy and Competitiveness.

\section{REFERENCES}

Abegaz B.M. et al. Chalcones and other constituents of Dorstenia prorepens and Dorstenia zenkeri. Phytochemistry. 2002:59:877-83. 
Austin M.B., Noel J.P. The chalcone synthase superfamily of type III polyketide synthases. Nat Prod Rep. 2003;20:79110. .

Ayabe S., Akashi T. Cytochrome P450s in flavonoid metabolism. Phytochem Rev. 2006;5:271-82.

Bhatt P., Dayal R. Stipulin, a prenylated chalcone from Dalbergia stipulacea. Phytochemistry. 1992;31:719-21.

Brazier M. et al. O-Glucosyltransferase activities toward phenolic natural products and xenobiotics in wheat and herbicide-resistant and herbicide-susceptible black-grass (Alopecurus myosuroides). Phytochemistry. 2002;59:149-56.

Chen S., Schopfer P. Hydroxyl-radical production in physiological reactions. A novel function of peroxidase. Eur J. Biochem. 1999;260:726-35.

Chen W. et al. Effects of root-applied naringenin and chalcone on the growth of annual plants. Weed Biol Manage. 2004;4:235-8.

Chen W. et al. The rates of maize growth and lignin biosynthesis change after root-applied chalcone. Weed Biol Manage. 2005;5:118-22.

Chen W. et al. Chalcone suppresses lignin biosynthesis in illuminated soybean cells. Weed Biol Manage. 2011;11:4956.

Copping L.G., Duke S.O. Natural products that have been used commercially as crop protection agents. Pest Manage Sci. 63, n.6, p.524-554, 2007.

Dayan F.E. et al. Natural products in crop protection. Bioorg Medic Chem. 2009;17:4022-34.

Dewick P.M. The biosynthesis of C5-C25 terpenoid compounds. Nat Prod Rep. 2002;19:181-222.

Díaz-Tielas C. et al. The natural compound trans-chalcone induces programmed cell death in Arabidopsis thaliana roots. Plant Cell Environ. 2012;35:1500-17.

Díaz-Tielas C. et al. Phytotoxic potential of trans-chalcone on crop plants and model species. J Plant Growth Regul. 2013;33:181-94.

Duke S.O. et al. Natural products as sources for new mechanisms of herbicidal action. Crop Protec. 2000;19:5839.

Friis-Møller A. et al. In vitro antimycobacterial and antilegionella activity of licochalcone A from Chinese licorice roots. Planta Medica. 2002;68:416-9.

Planta Daninha, Viçosa-MG, v. 34, n. 3, p. 607-616, 2016
Furusawa J. et al. Glycyrrhiza inflata-derived chalcones, Licochalcone A, Licochalcone B and Licochalcone D, inhibit phosphorylation of NF-êB p65 in LPS signaling pathway. Inter Immunoph. 2009;9:499-507.

Gafner S. et al. Antifungal and antibacterial chalcones from Myrica serrata. Planta Medica. 1996;62:67-69.

González J.A., Estévez-Braun A. Effect of (E)-chalcone on potato-cyst nematodes (Globodera pallida and $G$. rostochiensis). J Agric Food Chem. 1998;46:1163-5.

Harborne J.B. Comparative biochemistry of the flavonoids-I. Distribution of chalcone and aurone pigments in plants. Phytochemistry. 1966;5:111-5.

Iwashina T. The structure and distribution of the flavonoids in plants. J Plant Res. 2000;113:287-99.

Jayasinghe L. et al. Geranyl chalcone derivatives with antifungal and radical scavenging properties from the leaves of Artocarpus nobilis. Phytochemistry. 2004;65:1287-90.

Jimenez C.M. et al. Isolation, identification and usefulness of antifungal compounds from Zuccagnia punctata for control of toxigenic ear rot pathogens. Nat Prod Commun.

2014;9:1461-4.

Kachadourian R., Day B.J. Flavonoid-induced glutathione depletion: potential implications for cancer treatment. Free Rad Biol Med. 2006;41:65-76.

Kumar R. et al. Chalcones as promising pesticidal agents against diamondback moth (Plutella xylostella): microwaveassisted synthesis and structure-activity relationship. Med Chem Res. 2012;21:922-31.

Lee D. et al. Synthesis and biological evaluation of chalcone analogues as protective agents against cisplatin-induced cytotoxicity in kidney cells. Bioorg Med Chem Letters. 2015;25:1929-32.

Li Y-P. et al. Prenylated chalcones from Desmodium renifolium. Phytochem Letters. 2014;9:41-5.

Lin Y-M. et al. Chalcones and flavonoids as anti-tuberculosis agents. Bioorg Med Chem. 2002;10:2795-802.

Macías F.A. et al. Bioactive flavonoids from Helianthus annuus cultivars. Phytochemistry. 1997;45:683-7.

Magnusson M. et al. Pesticide contamination and phytotoxicity of sediment interstitial water to tropical benthic microalgae. Water Res. 2013;47:5211-21. 
Malhotra B. et al. Inhibition of tomato ringspot virus by flavonoids. Phytochemistry. 1996;43:1271-6.

Maxwell C.A. et al. A chalcone and two related flavonoids released from alfalfa roots induce nod genes of Rhizobium meliloti. Plant Physiol. 1989;91:842-7.

Motani K. et al. Proteomic analysis of apoptosis induced by xanthoangelol, a major constituent of Angelica keiskei, in neuroblastoma. Biol Pharm Bull. 2008;31:618-26.

Ni L. et al. Recent advances in therapeutic chalcones. Exp Opinion Therap Patents. 2004;14:1669-91.

Nishimura R. et al. Isobavachalcone, a chalcone constituent of Angelica keiskei, induces apoptosis in neuroblastoma. Biol Pharm Bull. 2007;30:1878-83.

Nunes A.S. et al. Activity of chalcones derived from 2,4,5trimethoxybenzaldehyde against Meloidogyne exigua and in silico interaction of one chalcone with a putative caffeic acid 3-O-methyltransferase from Meloidogyne incognita. Exper Parasitol. 2013;135:661-8.

Onylagha J.C. et al. Comparative studies of inhibitory activities of chalcones on tomato ringspot virus (ToRSV). Canadian J Plant Pathol. 1997;19:133-7.

Orlikova B. et al. Dietary chalcones with chemopreventive and chemotherapeutic potential. Genes Nutr. 2011;6:125-47.

Pan L. et al. Xanthohumol induces apoptosis in cultured 4016 human colon cancer cells by activation of the death receptor- and mitochondrial pathway. Molec Nutr Food Res. 2005;49:837-43.

Pesce S. et al. Effects of organic herbicides on phototrophic microbial communities in freshwater ecosystems. Rev

Environ Contam Toxicol. 2011;214:87-124.

Piñero J. et al. New administration model of trans-chalcone biodegradable polymers for the treatment of experimental leishmaniasis. Acta Trop. 2006;98:59-65.

Powles S.B., Yu Q. Evolution in action: plants resistant to herbicides. Ann Rev Plant Biol. 2010;61:317-47.

Prashar H. et al. Chalcone as a versatile moiety for diverse pharmacological activities. Inter J Pharm Sci Res. 2012;3:13-1927.

Rao G.P. et al. Efficacy of chalcone, hydrazide and oxadiazole derivatives against fungal pathogens of sugarcane. Sugar Cane. 1994;5:17-22.
Redl K. et al. Chalcone glycosides from Bidens campylotheca. Phytochemistry. 1993;32:218-20.

Sakai T. et al. Flavokawain B, a kava chalcone, induces apoptosis in synovial sarcoma cell lines. J Orthop Res. 2012;30:1045-50.

De La Rosa L.A., Alvarez-Parrilla E., Gonzalez-Aguilar G.A., editors. Fruit and vegetable phytochemicals: chemistry, nutritional value and stability. Ames: Blackwell Publishing, 2009. 384p.

Sahu N.K. et al. Exploring pharmacological significance of chalcone scaffold: A review. Curr Medic Chem. 2012;19:209-25.

Shang X. et al. The genus Scutellaria an ethnopharmacological and phytochemical review. J Ethnopharm. 2010;128:279313 .

Shang Y. et al. Chalcones from the flowers of Coreopsis lanceolata and their in vitro antioxidative activity. Planta Medica. 79:295-300.

Sharma N. et al. Stilbene-chalcone hybrids: design, synthesis, and evaluation as a new class of antimalarial scaffolds that trigger cell death through stage specific apoptosis. J Med Chem. 2012;55:297-311.

Simmonds M.S. et al. Insect antifeedant activity associated with compounds isolated from species of Lonchocarpus and Tephrosia. J Chem Ecol. 1990;16:365-80.

Star A.E. Frond exudate flavonoids as allelopathic agents in Pityrogramma. Bull Torrey Bot Club. 1980;107:146-53.

Svetaz L. et al. Antifungal chalcones and new caffeic acid esters from Zuccagnia punctata acting against soybean infecting fungi. J Agric Food Chem. 2004;52:3297-300.

Thirunarayanan G., Vanangamudi G. Synthesis, spectral studies, antimicrobial and insect antifeedant activities of some substituted styryl 42 -fluorophenyl ketones. Arabian J Chem. 2014;7:1055-64.

Verpoorte R., Alfermann A.W. Metabolic engineering of plant secondary metabolism. Dordrecht: Kluwer Academy, 2000. 286p.

Yang Y. et al. Two new chalcones from leaves of Morus alba L. Fitoterapia. 2010;81:614-6.

Yu O., Jez J.M. Nature's assembly line: biosynthesis of simple phenylpropanoids and polyketides. Plant $\mathbf{J}$. 2008;54:750-62. 
Yun M-S. et al. Selective growth suppression of five annual plant species by chalcone and naringenin correlates with the total amount of 4-coumarate: coenzyme A ligase. Weed Biol Manage. 2009;9:27-37.

Zhang E. et al. An update on antitumor activity of naturally occurring chalcones. Evidence-Based. Compl Altern Med. 2013;2013:1-22
Zhong P. et al. Blockage of ROS and NF-êB-mediated inflammation by a new chalcone $\mathrm{L} 6 \mathrm{H} 9$ protects cardiomyocytes from hyperglycemia-induced injuries. Biochim Biophy Acta. 2015;1852:1230-41.

Zhou B., Xing C. Diverse molecular targets for chalcones with varied bioactivities. Med Chem. 2015;5:388-404. 